\title{
Fatigue of Yttria-Stabilized Zirconia: II, Crack Propagation, Fatigue Striations, and Short-Crack Behavior
}

\author{
Shih-Yu Liu* and I-Wei Chen* \\ Department of Materials Science and Engineering. The University of Michigan, \\ Ann Arbor, Michigan 48109-2136
}

Fatigue crack propagation in 3Y-TZP was investigated using controlled surface flaws. A unique growth law strongly dependent on the maximum stress intensity factor and quadratically dependent on the amplitude of the range of stress intensity factor was established. This growth law was found to apply for both surface flaws and internal flaws and could be used to predict fatigue lifetime. The presence of residual stress altered the growth mechanics so that an inverse growth rate dependence on the applied stress, reminiscent of the so-called "short-crack behavior," was manifested. Fatigue striations resulting from alternate overload fracture and fatigue fracture during stress cycling were observed. The appearance of striations varied with the $R$ ratio and was very sensitive to the loading condition and crack geometry. [Key words: fatigue, fracture, zirconia, cracks, striations.]

\section{Introduction}

$\mathbf{T}$ HE importance of fatigue crack propagation in engineering ceramics has been recognized in recent years. ${ }^{1-3}$ The most complete studies on this subject to date are on magnesiapartially-stabilized zirconia (Mg-PSZ), ${ }^{3-13}$ a transformationtoughened ceramic which has a coarse-grained microstructure containing transformable inclusions. Similar but less comprehensive studies have been reported for alumina, ${ }^{1,2,14-21}$ ceriastabilized tetragonal polycrystals (Ce-TZP), ${ }^{2,23}$ and silicon nitride. ${ }^{24-33}$ These studies have established the accelerating effects of cyclic loading on crack growth. Importantly, a common characteristic of fatigue crack growth in ceramics is an extremely steep dependence of the growth rate on the stress intensity factor or its amplitude. Yet, examinations of the fracture surface have thus far revealed no special feature that distinguishes fatigue crack growth from overload fracture. These observations are in contrast with the phenomenology established for other engineering materials such as metals and polymers. ${ }^{34}$

At the present time, considerable confusion on the interpretation of the fatigue crack growth rate data still exists. For example, Dauskardt et al. ${ }^{10}$ have shown that for Mg-PSZ the fatigue crack growth rate is proportional to the amplitude of the stress intensity range $(\Delta K)$ raised to the $m$ th power, i.e.,

$$
\mathrm{d} a / \mathrm{d} N=A(\Delta K)^{m}
$$

where $A$ is a constant. For sufficiently small $R$ ratios, they

D. B. Marshall - contributing editor

\footnotetext{
Manuscript No. 197313. Received September 7, 1990; approved February 28,1991 .

Presented at the 92nd Annual Meeting of the American Ceramic Society, Dallas, TX, April 25, 1990 (Paper No. 3-JXX-90).

Supported by the U.S. National Science Foundation under Grant No. DMR-8807024.

*Member, American Ceramic Society.
}

further propose that, mechanistically, $\Delta K$ should be identified with its value at the crack tip, $\Delta K_{\text {tip }}$, which is related to the maximum stress intensity factor $\left(K_{\max }\right)$ by subtracting a shielding stress intensity factor $\left(K_{\mathrm{s}}\right)$,

$$
\Delta K_{\text {tip }}=K_{\max }-K_{\mathrm{s}}
$$

From additional experiments, they also suggest that $K_{\mathrm{s}}$ be proportional to $K_{\max }$, i.e.,

$$
K_{\mathrm{s}}=\beta K_{\max }
$$

where $\beta$ is a constant. Therefore, by combining Eqs. (1) to (3), we can rewrite the crack growth rate as

$$
\mathrm{d} a / \mathrm{d} N=A\left[(1-\beta) K_{\max }\right]^{m}
$$

which would appear to be independent of the stress intensity amplitude, $\Delta K$, and the $R$ ratio. However, their limited data on the $R$ ratio effect seemed to contradict the above notion. ${ }^{10}$ Also disconcerting is the recent report by Reece et $a l^{20}$ on alumina which calls into question the validity of fracture mechanics parameters, such as the stress intensity factor, as appropriate loading parameters to correlate fatigue crack growth data. Lastly, evidence has been provided that small cracks may behave differently in fatigue and may even have an inverse and "unpredictable" growth rate dependence on the applied stress intensity factor. ${ }^{11}$ Since typical processing flaws in structural ceramics are much smaller than the long cracks employed in crack growth studies, one may question whether the long crack data should be used to predict the growth of natural flaws, which seems to determine the fatigue life of polycrystalline ceramics. The present paper is an attempt to provide the necessary experimental information to address these issues.

Direct measurement of the fatigue crack growth rate in an yttria-stabilized tetragonal zirconia polycrystal (3Y-TZP), a material studied in the companion paper, ${ }^{35}$ is reported in this study for controlled surface flaws, which are of a size of several hundred micrometers. As noted in the previous paper, 3Y-TZP has only rather limited transformation plasticity and relatively modest fracture toughness but very high strength. Its very fine grain size (less than $0.5 \mu \mathrm{m}$ ) and the nearly cubic (with a tetragonality of only 1.013) single-phase composition make available a homogeneous microstructure with very little residual stress. In this sense, 3Y-TZP may be considered to be a model for brittle polycrystalline ceramics. Our experiments were performed using a cantilever beam with a Vickers indent on the surface, cyclically stressed under the constant peak load condition. A wide range of $R$ ratios, defined as the ratio of the minimum stress intensity factor to the maximum stress intensity factor, were studied in order to provide insight into the relative importance of mean stress and stress amplitude. The effect of residual stress and the novel observation of fatigue striations in a ceramic material have also been investigated. Lastly, these data are compared with fatigue lifetimes reported in the companion paper to establish a methodology for lifetime prediction. 


\section{Experimental Procedure}

\section{(1) Material and Its Fracture Toughness}

The material studied was a sintered zirconia containing $3 \mathrm{~mol} \%$ yttria (3Y-TZP) with a grain size of about $0.38 \mu \mathrm{m}$. The specimens used were cut from the same batch of material studied in the previous paper, ${ }^{35}$ and several details of this material were already described there. To characterize the fracture behavior in monotonic loading, the $R$-curve (crack resistance curve) was first measured using two techniques. The first one used a specimen containing an indentation crack similar to those used in fatigue testing described in the next two sections. In this method, the residual stress due to indentation was first removed by annealing. The specimen was then loaded to cause certain crack propagation. After the crack length was measured, the loading was resumed to a higher value to cause further crack growth. This procedure was repeated until the specimen failed. In the second method, ${ }^{36}$ a series of indents of different sizes were first introduced to a four-point-bend specimen. After annealing, the specimen was loaded to fracture. By measuring the initial and final crack lengths of those surviving indentation cracks, fracture resistance at various crack length increments was determined. The results of these $R$-curve measurements are shown in Fig. 1. Consistent with the very fine microstructure and the relatively narrow transformation zone of this ceramic, the $R$-curve rises steeply during the first $20-\mu \mathrm{m}$ extension of the crack. Such a feature is believed to be representative of brittle crystalline ceramics, although it is not usually observed in the tougher ceramics (Mg-PSZ, coarse-grained alumina, Ce-TZP, and some silicon nitride).

\section{(2) Specimen Preparation}

A rectangular plate with dimensions of $25 \mathrm{~mm} \times 10 \mathrm{~mm} \times$ $1 \mathrm{~mm}$ was used for fatigue tests. The surface of the specimen was finely ground and then polished using a $1-\mu \mathrm{m}$-diamond paste in order to provide a good finish. A Vickers indent was placed on the polished surface at a load of $20 \mathrm{~kg}$ and was carefully aligned so that two opposite corner cracks were perpendicular to the long axis of the specimen. These specimens were annealed at $1200^{\circ} \mathrm{C}$ for $10 \mathrm{~min}$ and then slowly cooled to room temperature to remove the residual stress around the indent. No change in grain size, microstructure, or phase content was detected from this annealing process. Some specimens were left unannealed to explore the effects of residual stress on fatigue behavior.

\section{(3) Fatigue Testing}

Cyclic cantilever bending fatigue tests were conducted using an MTS machine operated under load control, with a
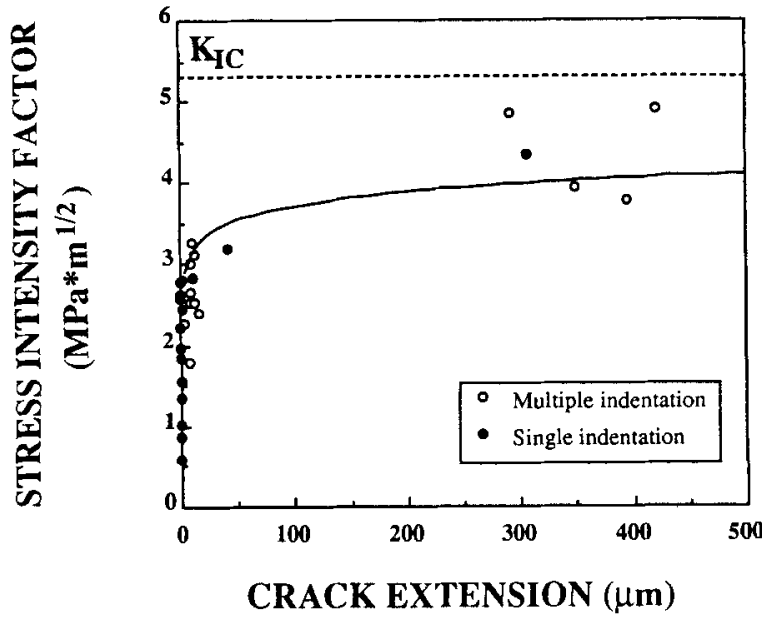

Fig. 1. Crack resistance curve of 3Y-TZP ( $K_{\text {IC }}$ shown obtained from indentation method ${ }^{35}$ ). sinusoidal wave form of $3 \mathrm{~Hz}$. For each experiment, a set of constant maximum and minimum loads was chosen. The crack length was measured periodically by a replication technique. This was done by spraying acetone onto the specimen surface and then covering it with an acetylcellulose film. ${ }^{\dagger}$ During this procedure, a tensile load of $80 \%$ of the peak load was maintained so that the crack remained open. Usually two replicas were taken for each measurement; no systematic difference between their crack lengths was observed.

Because of the crack propagation, the amplitude of the stress intensity factor increases even though the maximum and minimum loads remained unchanged. The $R$ ratio, defined as the ratio of the minimum to maximum stress intensity factors, remains constant.

\section{Experimental Results and Analysis}

\section{(1) Crack Geometry and Stress Intensity Factor}

A micrograph of a surface crack, initiated by a Vickers indent and grown under a cyclic fatigue load, is shown in Fig. 2. Stable propagation of the two horizontal indentation cracks is evident. As noted previously, the fatigue crack growth rate in ceramics is extremely sensitive to the stress intensity factor. Thus, the even propagation of the two highly stressed cracks provided a strong indication of the existence of a uniform stress state. In this study, we have used such observations to determine whether a good alignment of the indentation cracks and the loading train was achieved.

The shape of the surface crack is better illustrated by the micrograph of the fracture surface shown in Fig. 3. It reveals

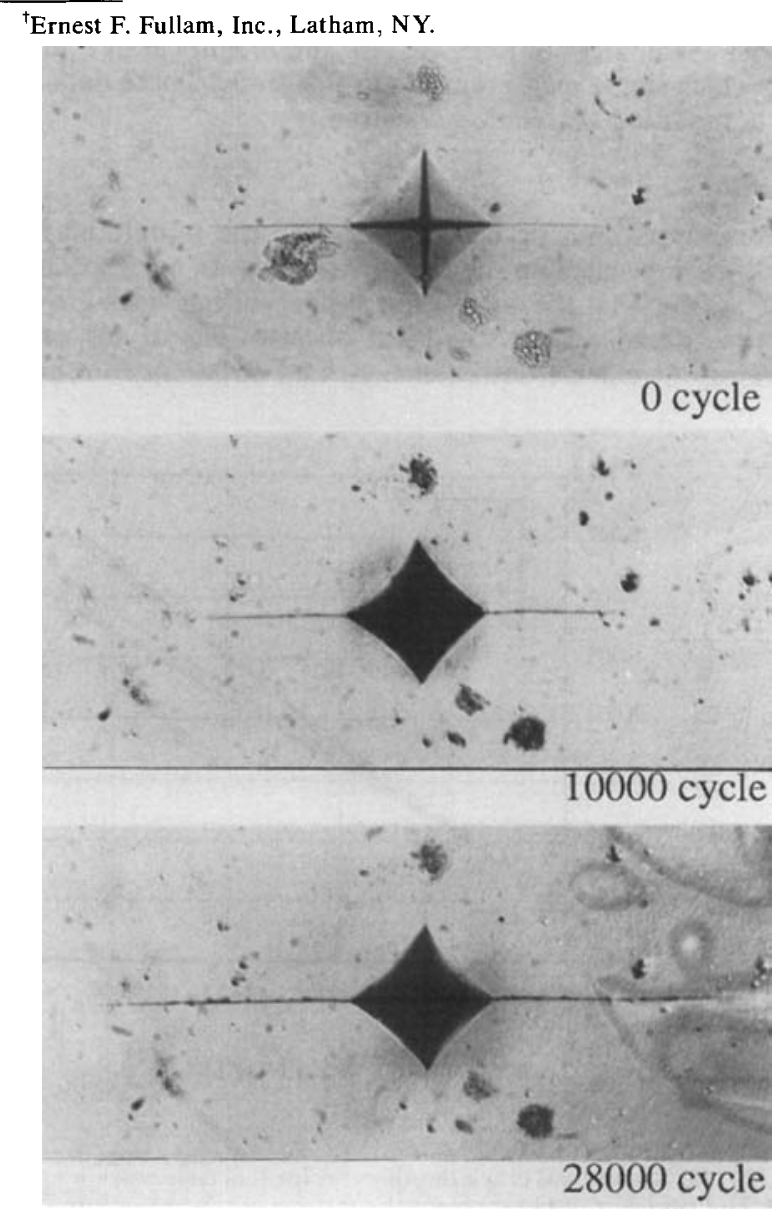

Fig. 2. Optical micrographs of replica showing the stable crack propagation of an indent crack in cyclic bending. 


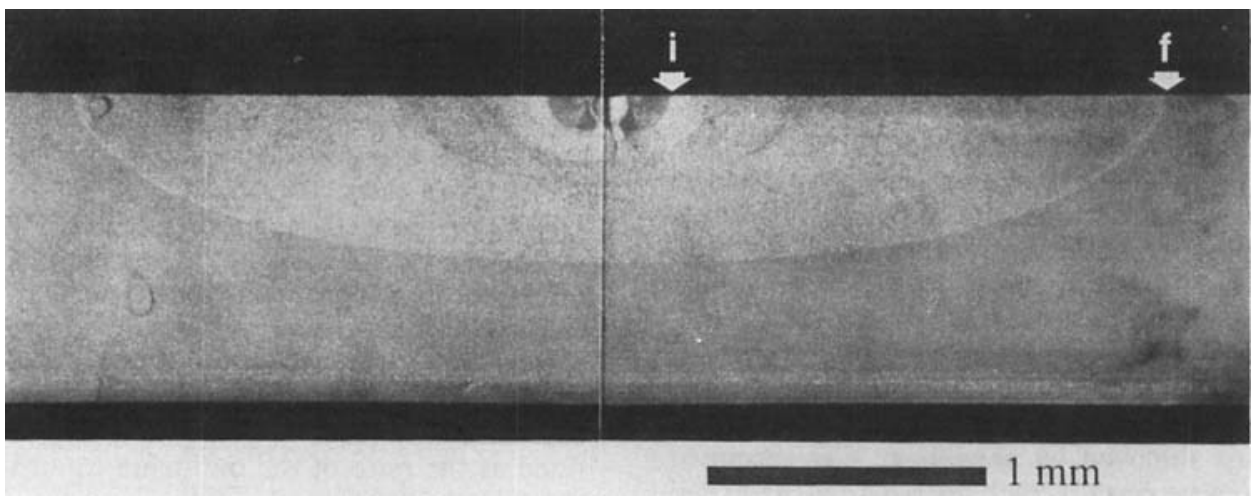

Fig. 3. Fatigue fracture surface of $3 Y-T Z P$. Note the shape change, from initial indent crack indicated by " $\mathrm{i}$ " to the final fatigue crack indicated by "f".

a well-defined, semi-elliptical initial indentation crack, having an aspect ratio of 1.5 . This is indicated in Fig. 3 by an arrow marked "i". Under fatigue loading, the crack grew stably until it reached the size marked "f"; subsequent crack propagation was unstable, leading to catastrophic fracture. The aspect ratio at the point marked " $\mathrm{f}$ " is 3 .

Since the stress intensity factor along the edge of an elliptical surface crack is highly sensitive to the aspect ratio, a large error in estimating the stress intensity factor will result if the variation of the aspect ratio is not considered. ASTM E740 ${ }^{37}$ recommends the following empirical equation to correlate the shape of a semi-elliptical surface crack growing under bending:

$$
1 / b=(1 / a)+(1 / t)
$$

where $a$ is the length of the major axis, $b$ is the length of the minor axis, and $t$ is the specimen thickness. In Fig. 4(a), under various loading conditions, we plot the reciprocal of $a$ and $b$ from crack shape measurements in this study. These data suggest a modified correlation equation

$$
t / b=p(t / a)+q
$$

where $p$ and $q$ may be determined from the initial and final crack sizes revealed on the fracture surfaces of each specimen if we assume that the correlation applies during crack growth. (In the special case when direct observations of successive markings of crack front extension, i.e., striations, are avail-

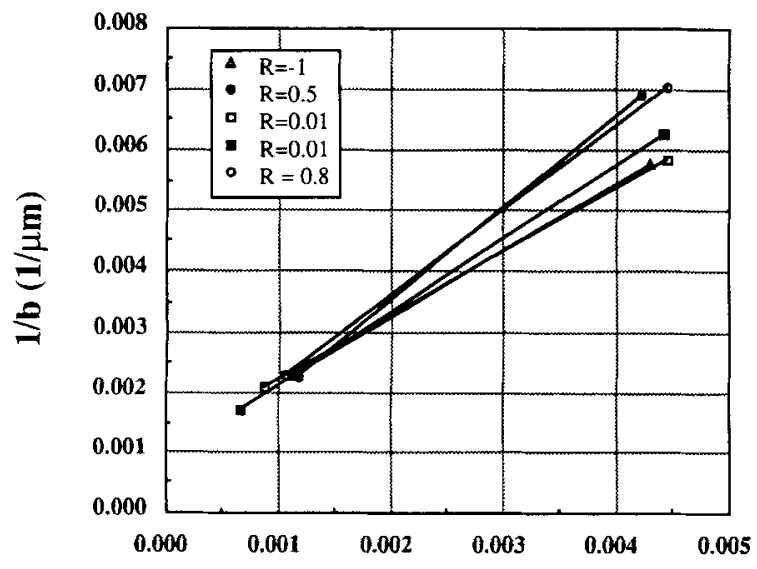

$1 / \mathbf{a}(1 / \mu \mathbf{m})$

(a) able, such a linear relation has been verified; see Fig. 4(b) and Section III(4).) Using this method, we have evaluated the crack depth with Eq. (6) from the surface crack length measurement. The stress intensity factor at the crack tip can then be calculated from the equation in Ref. 37 for elliptical cracks. Indeed, we can use Eq. (6) to rewrite $K$ as a function of $a$ only. The $K-a$ correlation, however, is not unique, since $p$ and $q$, determined from the initial and final crack sizes, are usually different from specimen to specimen. (The $K-a-b$ correlation is unique, of course. ${ }^{38}$ ) Typically, we find $K$ is proportional to $a^{n}$ within a narrow range of $a$, where $n$ is around 0.3 . This contrasts with the case of a uniaxially loaded center crack which has $n=0.5$.

\section{(2) Crack Growth Acceleration}

To ascertain the contributions from cyclic vs static fatigue, we first compared crack propagation under a constant load and under a cyclic load. This was accomplished by introducing block loading into a cyclic loading schedule, as shown in Fig. 5. Crack growth was allowed to proceed under a cyclic load until point B in Fig. 5. Between B and C, under sustained loading, there was no crack extension even though the peak load was the same. (The stress intensity factor actually increased a little bit during crack propagation up to point $\mathbf{B}$ because of crack growth.) Apparently, the stress intensity factor provided by the constant load was below the threshold required for slow crack growth (i.e., static fatigue, as it is often referred to in the ceramic literature). Crack growth later

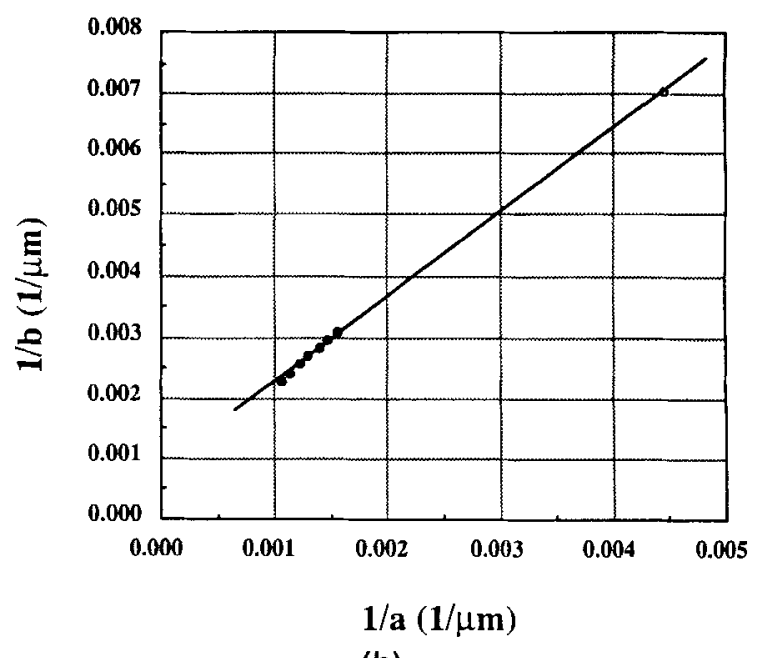

(b)

Fig. 4. (a) Reciprocal crack depth vs reciprocal half crack length in five specimens. The upper-right data represent initial indentation cracks and the lower-left data represent the fatigue crack just before failure. (b) Reciprocal crack depth vs reciprocal half crack length from one test. The upper-right datum represents the initial indentation crack and the lower-left data are derived from striations of a fatigue-growing crack just before failure. 

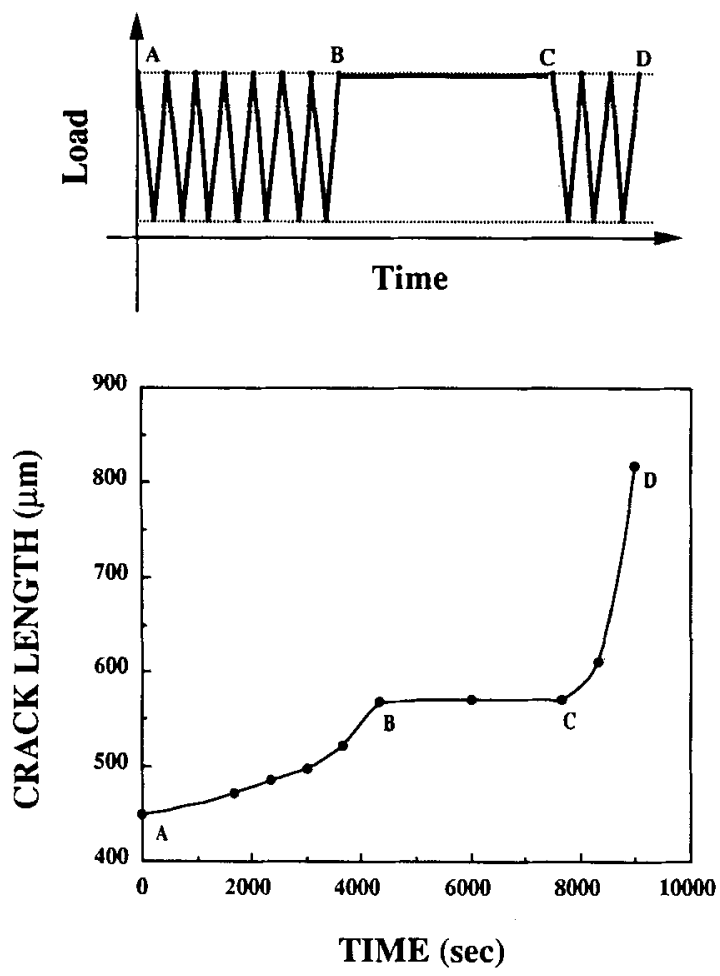

Fig. 5. Crack length during cyclic and block loading.

restarted at point $\mathrm{C}$ when the cyclic loading was resumed at the same peak load. In general, the experimental conditions of the present study were chosen so that static fatigue could be ignored compared to the cyclic fatigue effect.

\section{(3) The Roles of $K_{\max }$ and $\Delta K$}

The bending fatigue crack growth data under constant maximum load and $R$ ratio are shown in Fig. 6. Each set of data was from a single specimen. However, they were reproducible as exemplified by the case of $R=0.01$ for which data from two specimens are shown. Also shown are the inferred crack growth rate, under the same $R$ ratio, from the fatigue lifetime data reported in the previous paper. ${ }^{35}$ (In the latter work, when inferring the crack growth rate, we have assumed that the lifetime of a smooth bar specimen undergoing uniaxial tension-compression cycling is governed by crack growth only. A growth equation of the form of Eq. (1) is then used to deduce the crack growth rate using a reasonable value of the initial crack size $(25 \mu \mathrm{m})$ estimated from fractography. $\left.{ }^{35}\right)$ The

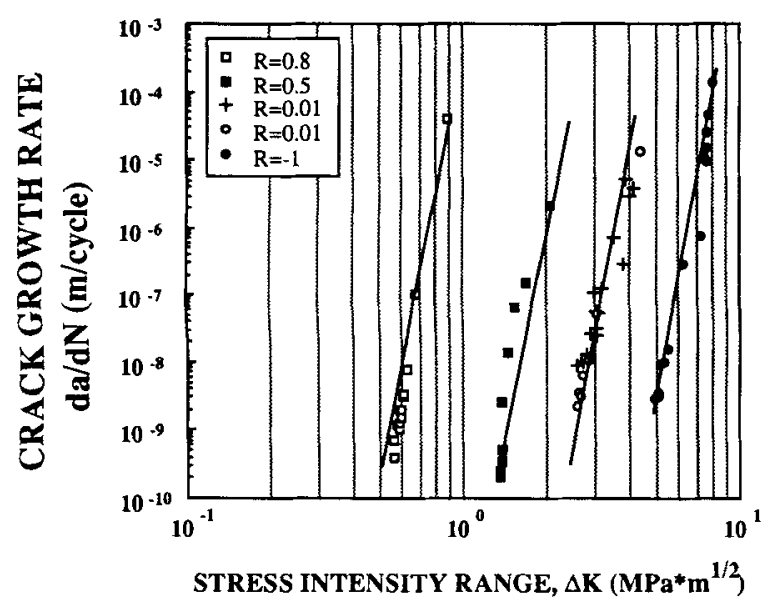

Fig. 6. Fatigue crack growth rate vs stress intensity range. Solid lines show the predictions from Ref. 35 . two sets of data are in rather good agreement. A further demonstration of this agreement is provided by Table $\mathrm{I}$, in which the prefactor $A$ of Eq. (1) is estimated from the surface crack growth data of Fig. 6 while setting $m=21$. Using Table III in the previous paper, which also provides information of the prefactor $\boldsymbol{A}$ from lifetime data, we can determine a constant $Z$ as defined in the previous paper and hence the initial crack length in the smooth bar studied there (see Eq. (8) of the previous paper). These values of the initial crack size and length are listed in Table I. The average initial crack size, $22 \mu \mathrm{m}$, nearly coincides with the one inferred from fractography, $25 \mu \mathrm{m}$.

The fatigue data exhibit the characteristically steep dependence of the crack growth rate on the amplitude of the stress intensity factor. In the present case, the slope is about 21 and is independent of the $R$ ratio. The above slope is very similar, perhaps fortuitously so, to the value reported for Mg-PSZ by Ritchie and co-workers. ${ }^{3,10-12}$ It should be noted that the effect of the $R$ ratio is rather strong, compared to the data for metals. ${ }^{34}$ (For a typical metal such as aluminum, an increase of $R$ from 0.2 to 0.8 increases the growth rate by a factor of 4 , compared to a factor of 200 in the present material.) A similarly strong effect of the $R$ ratio on fatigue life was previously observed in the companion paper and was attributed to the strong dependence on the maximum stress. ${ }^{35}$ Taking a similar approach, we find that this strong dependence can be largely attributed to a strong dependence on the maximum stress intensity factor $\left(K_{\max }\right)$. As shown in Fig. 7 by plotting crack growth data against $K_{\max }$, the data with different $R$ ratios can be brought into better accordance, although some systematic difference between them (showing a higher $\mathrm{d} a / \mathrm{d} N$ at a lower $R$ ratio) is still apparent. This latter difference can be removed if we reconsider the contributions of $\Delta K$ by allowing for a weak dependence of $\mathrm{d} a / \mathrm{d} N$ on $\Delta K$. This is equivalent to introducing a factor $(1-R)$ to a certain power in the growth equation. The best choice was found when we factored out a constant $(1-R)^{2}$ from each data set of $\mathrm{d} a / \mathrm{d} N$, as shown in Fig. 8, which caused the normalized data for different $R$ ratios to cluster around a single line. Thus, the fatigue growth rate can be represented by the following equation:

$$
\mathrm{d} a / \mathrm{d} N=A^{\prime} K_{\max }^{m-2} \Delta K^{2}
$$

where $m=21$, as in the growth equation deduced in the previous paper and $A^{\prime}$ is another constant. At the same $K_{\max }$, the lower the $R$ ratio, i.e., the higher the $\Delta K$, the higher the crack growth rate (Fig. 7). Thus, fatigue crack growth rate depends very strongly on the maximum stress intensity factor and modestly on the cyclic stress intensity factor, as was previously seen in the fatigue lifetime data ${ }^{35}$ The rationalization of the above growth equation will be provided in Section IV(2).

In addition to the crack growth data of 3Y-TZP, we have also plotted the data of Mg-PSZ provided by Dauskardt et al. ${ }^{10}$ They performed a set of fatigue crack growth experiments at a fixed $K_{\max }$, but with different $R$ ratios $(0.15,0.31,0.46)$ which gave growth rates of up to a factor of 20 times difference. Using Eq. (7), we are able to show all these data cluster into a single line in Fig. 8.

\section{(4) Fatigue Striations}

A common feature of fatigue crack growth in metals, at an intermediate stress intensity factor above the fatigue

Table I. Evaluation of Initial Crack Length

\begin{tabular}{cccc}
\hline$R$ & $\log (A)^{\dagger}$ & $\log (Z / A)^{\ddagger}$ & $a_{0}(\mu \mathrm{m})^{\frac{8}{8}}$ \\
\hline-1 & -23.245 & 58.05 & 27 \\
0.01 & -16.686 & 52.52 & 21 \\
0.5 & -12.084 & 48.00 & 21 \\
0.8 & -2.746 & 38.87 & 20 \\
\hline
\end{tabular}

${ }^{\dagger}$ Intercept of best-fit line of data in Fig. $6 .{ }^{*}$ Data from Table III in Ref. 35 ${ }^{8}$ Calculated by using Eq. (8) in Ref. 35 . 


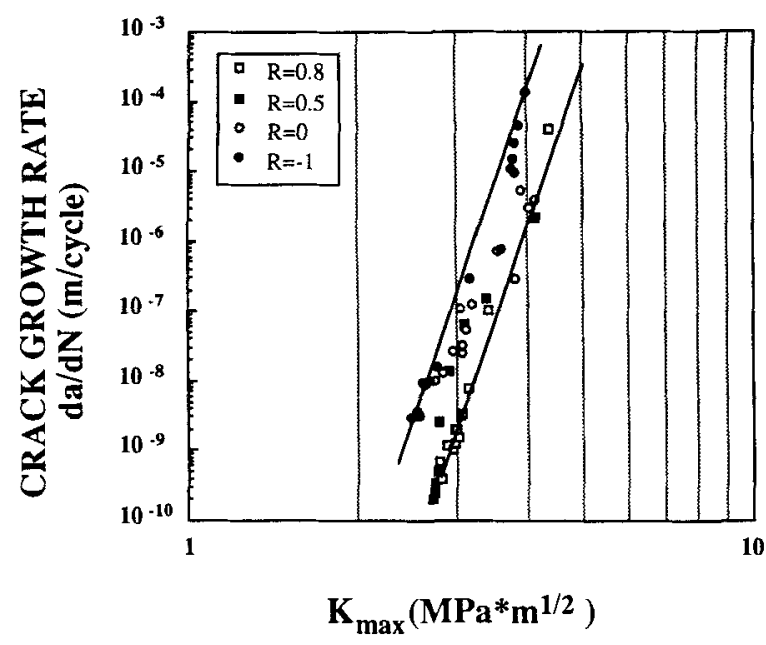

Fig. 7. Fatigue crack growth rate vs maximum stress intensity factor. Crack growth rate is slightly higher at lower $R$ ratios.

threshold, is the appearance of striations which mark the cycle-to-cycle advance of the crack front. ${ }^{34}$ Such fatigue striations have not been reported in the ceramic literature before. In our study of fatigue crack growth from controlled flaws, we were able to observe striations reproducibly under certain conditions. An example is shown in Fig. 9(a), which was obtained between $K_{\max }=4.3$ and $5 \mathrm{MPa} \cdot \mathrm{m}^{1 / 2}$ at $R=0.8$. A very good one-to-one correspondence between stress cycle and striation was found for the last 10 cycles in this case, for a crack growth rate of about 40 to $65 \mu \mathrm{m}$ per cycle. This correspondence was ascertained because a surface replica had been taken at 10 cycles prior to failure in this case and, indeed, 10 striations were seen on the newly formed crack surface between then and the final fracture. (The aspect ratio of the advancing crack is plotted in Fig. $4(\mathrm{~b})$, which conforms to Eq. (6), as noted previously.) Similar striations were observed for $R=0.8,0.5$, and 0.01 (Figs. 9(b) and (c)) when the peak stress intensity factors were high enough, i.e., during the last scores of cycles before catastrophic failure.

Several interesting features have been noticed in these striations. First, by comparing micrographs of the two matching fracture surfaces, we have verified that they are symmetric in appearance (black vs black and white vs white, etc.) This implies that striations are not a signature of shear failure or cup-and-cone failure. Second, striations generally have a characteristic black/white contrast when viewed under a light

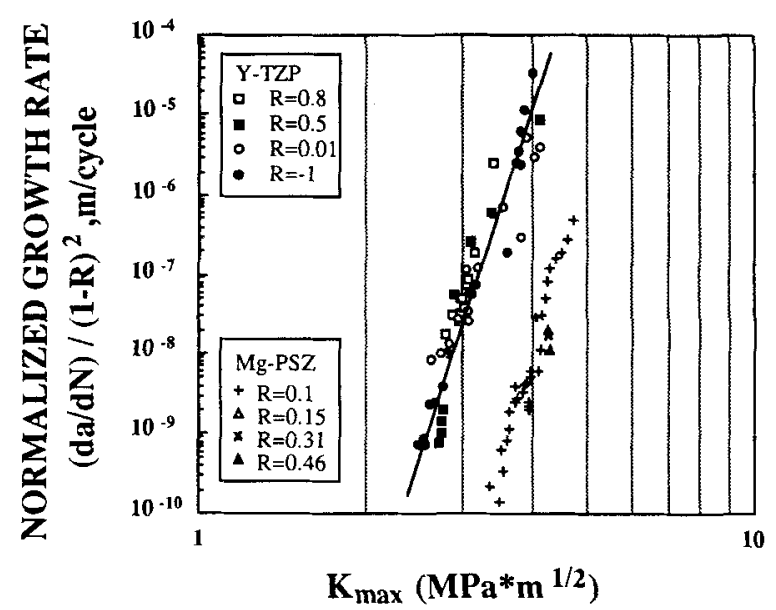

Fig. 8. Normalized fatigue crack growth rate vs maximum stress intensity factor for Y-TZP. No systematic dependence on $R$ ratio is evident. Fatigue data of Dauskardt $e t$ al. ${ }^{10}$ on $\mathrm{Mg}-\mathrm{PSZ}$ are also shown for comparison. microscope. Third, comparing crack growth along the major and minor axes of the semi-elliptical crack, striations in the minor axis direction are less distinct than ones along the major axis, especially at low $R$ ratios. These features are evident in Fig. 9(a).

We have computed for each striation the stress intensity factor and plotted it against the crack length. They are shown in Fig. 10 by open symbols. The smooth curves and the data points marked by filled symbols were computed from $K_{\{\mathrm{a}, \mathrm{b}\}}{ }^{38}$ using surface crack length (a) data and $\mathrm{Eq}$. (6) for the crack depth $(b)$. (These curves are different for each test because a different maximum load and crack geometry were used; i.e., $b$ is different at the same $a$ for each test.) For comparison, the crack resistance curve is also shown in Fig. 10. It is clear that fatigue striations are observed only when the peak stress intensity factor exceeds the crack resistance, $K_{\mathrm{r}}$, on the $R$-curve. This leads us to the important conclusion that the fatigue striations in our tests were the result of combined fatigue crack growth and $R$-curve-limited (overload) crack growth. In the following paragraphs, we will examine the mechanics aspects related to this observation.

As shown in Fig. 11, when the maximum applied stress and the crack geometry are appropriately chosen, the curve of maximum stress intensity and the $R$-curve may cross over twice. Three stages of crack propagation can then be identified. In stage I, the maximum stress intensity factor $\left(K_{\max }\right)$ exceeds the crack growth resistance $\left(K_{\mathrm{r}}\right)$. Therefore, for a certain period during loading in each cycle, crack growth progresses until it reaches the first intercept crack length, $a_{1}$. In our experiments, this regime was not significant because the range between the initial crack length and $a_{1}$ is probably very narrow. In stage II, $K_{\text {max }}<K_{\mathrm{r}}$ so that crack growth cannot take place without stress cycling. In this regime, crack propagation is solely due to fatigue. In stage III, $\mathrm{K}_{\max }$ once again exceeds $K_{\mathrm{r}}$. Moreover, both the $K_{\max }$ curve and the $K_{\mathrm{r}}$ curve have relatively flat slopes. As a result, rapid crack growth occurs only briefly at the higher stress end in a given cycle. Meanwhile, fatigue growth continues for the rest of the cycle when the stress intensity factor falls below $K_{\mathrm{r}}$. These two alternating growth steps are believed to be responsible for the black/white contrast observed along with striations toward the end of some bending fatigue tests.

The above interpretation of growth mechanics is consistent with the fractography observations, which are summarized schematically in Fig. 9(d). We will identify the black band with rapid growth above $K_{\mathrm{r}}$. This seems reasonable because its high velocity should give a similar appearance as that of the overload fracture, best represented by the black appearance of the fracture surface in catastrophic failure. On the other hand, the white contrast is identified with fatigue growth, which is consistent with the white appearance of the fracture surface before striations appear. Comparing fracture along the major and minor axes, we find less overload fracture appearance (black contrast) along the minor axis. This is because of the smaller $K_{\max }$, which allows fatigue crack growth but no overload crack growth. Furthermore, for very low $R$ ratios, such as $R=-1$ in Fig. 10, the accumulated damage due to fatigue is so pronounced and the fatigue growth so fast that catastrophic failure occurs within one or two cycles when $K_{\max }$ approximates $K_{r}$. As a result, no fatigue striations can be found on the fracture surface. Lastly, for the same $R$ ratio, fatigue striations may or may not be found depending on the relative values of $K_{\max }$ and $K_{\mathrm{r}}$. One interesting example is the two sets of data of $R=0.01$ in Fig. 10-the one with a higher $K_{\max }$ developed striations shown in Figs. 9(b) and (c) while the one with a lower $K_{\max }$ did not. Excluding the data in the striation stage (stage III), which will be discussed below, the crack growth rates of both tests fall on the same line, as shown in Fig. 6 (symbol "O" for the case of a higher $K_{\max }$; symbol “+" for the case of a lower $K_{\max }$ ). This once again demonstrates the unique growth rate depend- 


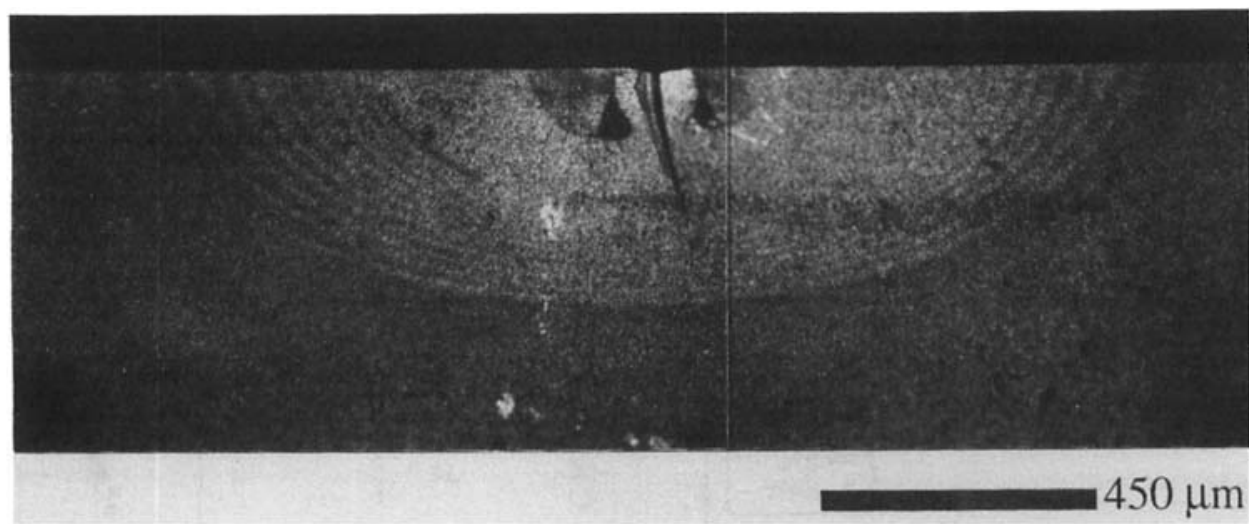

(a)

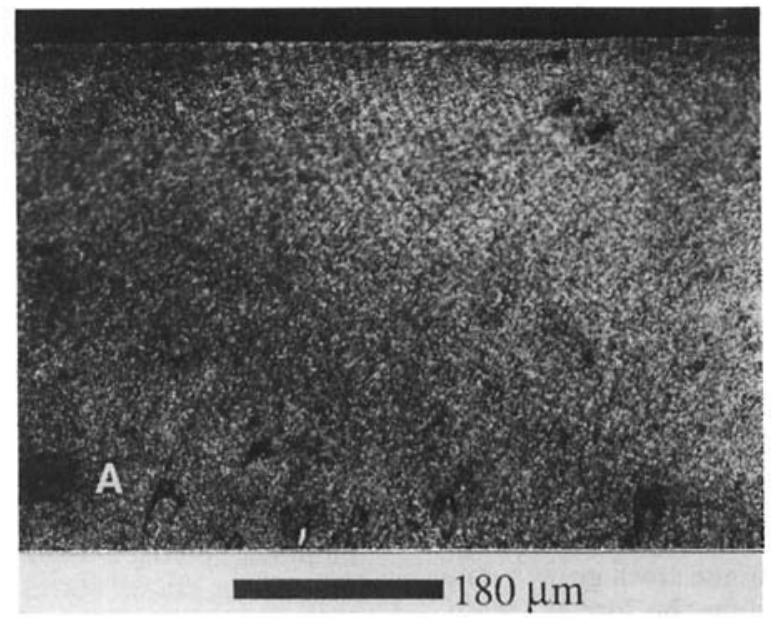

(b)
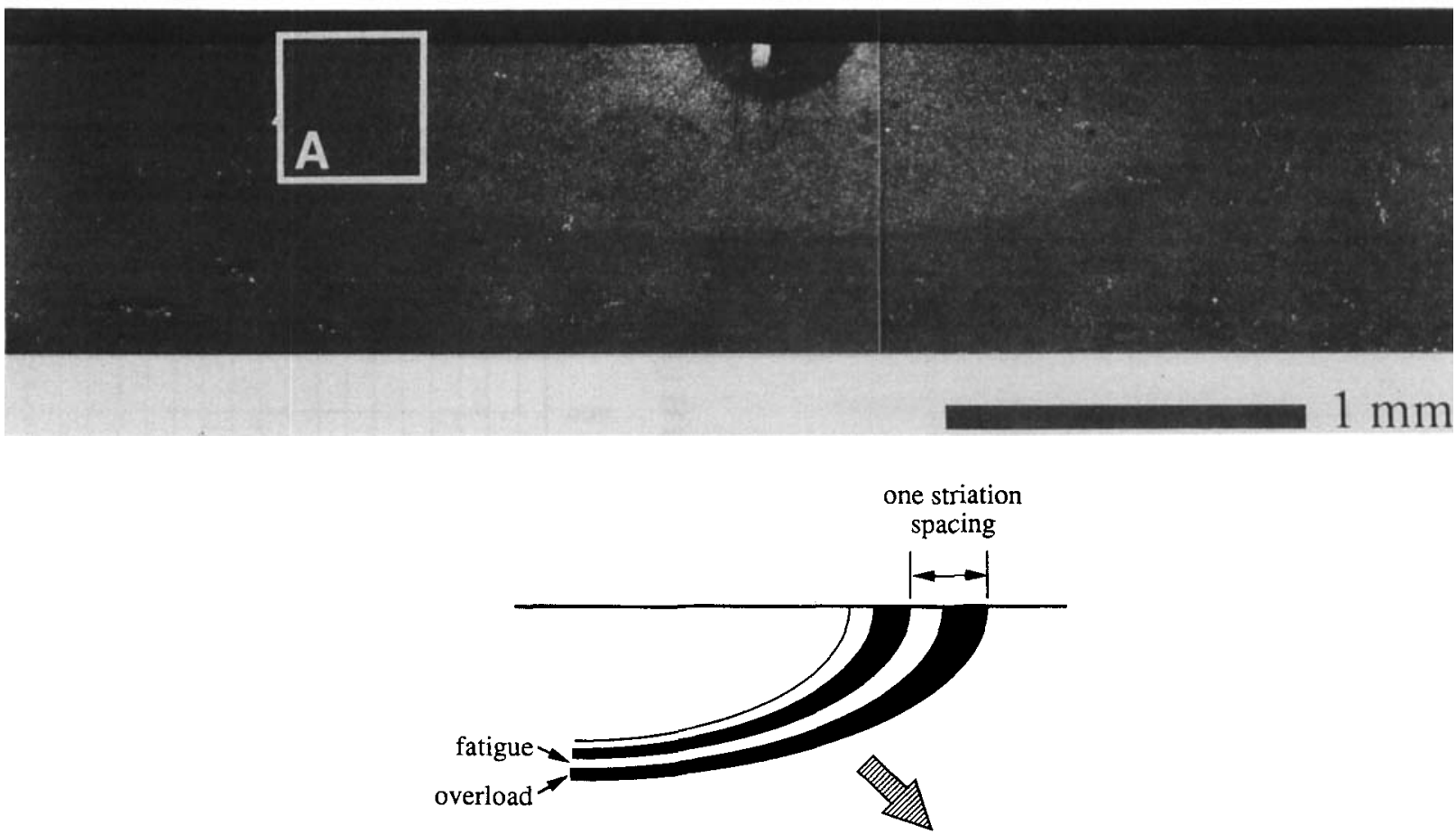

(d)

Fig. 9. Fatigue fracture surface of 3Y-TZP for (a) $R=0.8$ and (b, $c) R=0.01$. In both cases, fatigue striations appear during the last scores of cycles before catastrophic failure. (d) Schematic of fatigue striations in terms of two growth steps. 

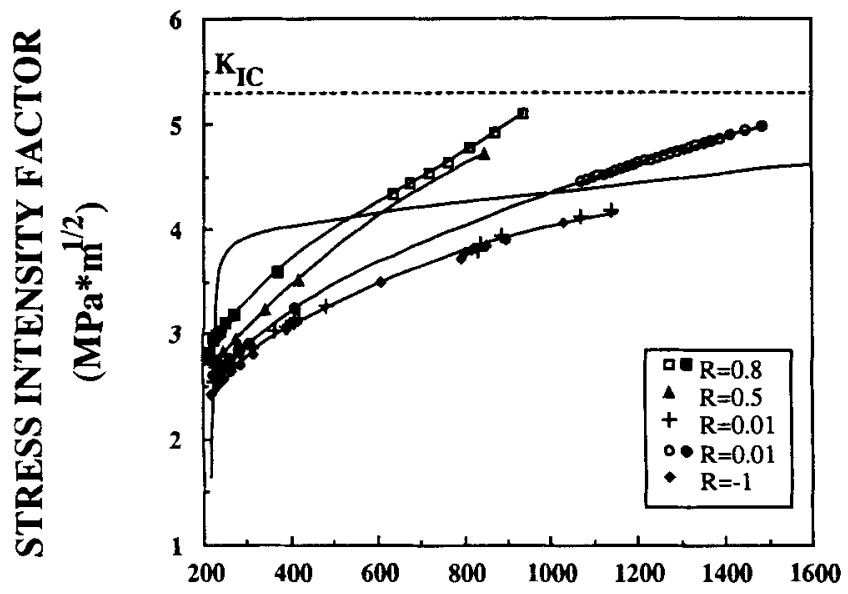

\section{HALF CRACK LENGTH $(\mu \mathrm{m})$}

Fig. 10. Maximum stress intensity factor vs half crack length. The two sets of data at $R=0.01$ were obtained using two different stress levels. Open symbols correspond to observations of striations.

ence on $K_{\max }$ at a given $R$ ratio whether stage III is experienced or not.

Since the crack growth rate in stage III has a contribution from a nonfatigue mechanism, it is expected to be faster. This expectation is born out by the data shown in Fig. 12. Here the open circles were obtained from the spacing between striations, while the filled circles were obtained from the width of the white band which corresponds to fatigue crack propagation (see Fig. 9(d)). The latter set of data (stage III) are in line with the other fatigue crack growth data measured at lower $K_{\max }$ (stage II), while the former clearly deviates from the trend established for lower $K$.

\section{(5) Fatigue Crack Propagation in a Residual Stress Field}

The results described above were from annealed specimens in which the residual stress was removed. To investigate the effect of a residual stress, we have conducted a parallel study using unannealed specimens. In Fig. 13, the crack extension curves of several specimens, one of them not annealed, are compared. It is evident that the shape of the curve of the latter specimen is distinctly different from the rest, in that although the crack in the unannealed specimen initially grew rapidly, it soon decelerated for some time before it accelerated again past the inflection point marked " $x$ ". A sigmoidal

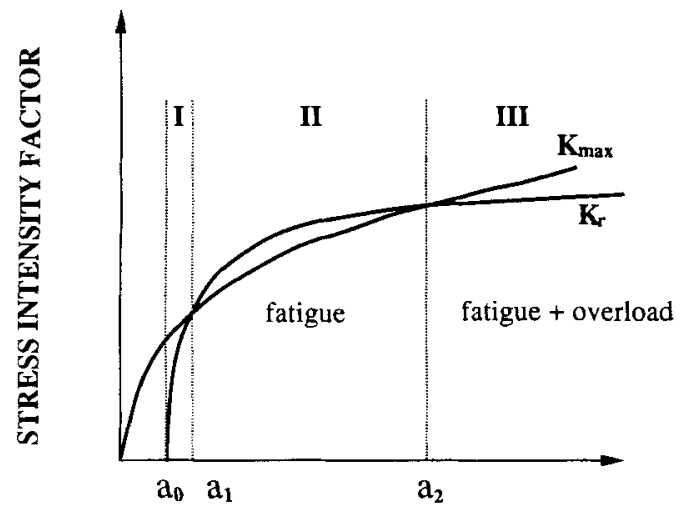

CRACK LENGTH

Fig. 11. Maximum stress intensity factor $\left(K_{\max }\right)$ and crack resistance $\left(K_{\mathrm{r}}\right)$ vs crack length: (I) growth due to overload, (II) growth due to fatigue, (III) growth due to overload and fatigue.

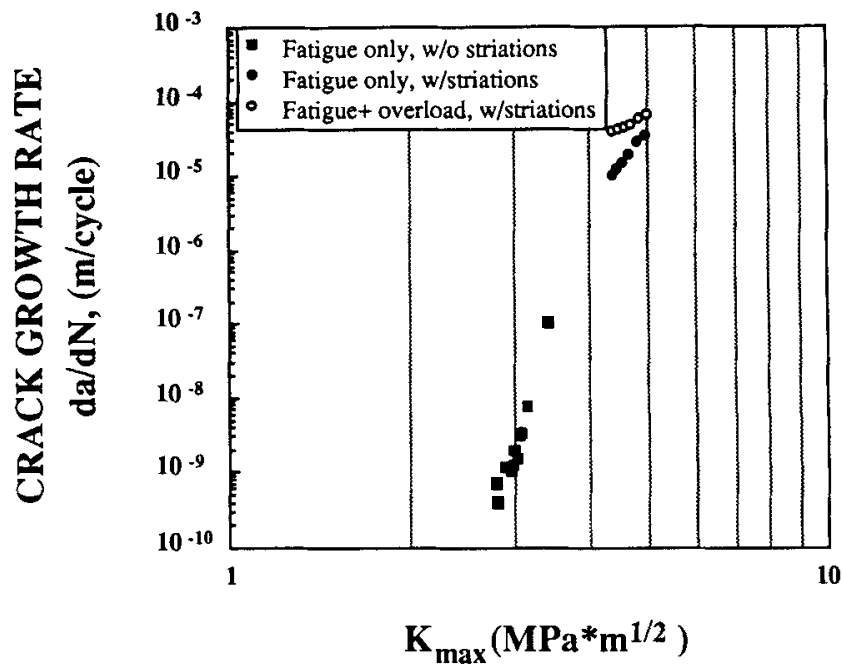

Fig. 12. Fatigue crack growth vs maximum stress intensity factor for a specimen showing fatigue striations: (i) stage II crack growth $(0,0)$ stage III crack growth.

shaped extension curve thus results. In contrast, the crack in all of the annealed specimens grew at an ever increasing velocity from the very beginning. (The shorter lifetime for the annealed specimens is due to a larger applied stress intensity factor, which is necessary for observing fatigue crack growth in this case, as will become clear later.)

The crack growth rate in the unannealed specimen has an unusual dependence on the applied stress intensity ( $K_{\text {appl }}$, which equals $\Delta K$ since $R=0$ in the test). This is shown in Fig. 14, where the growth rate is plotted against the maximum $K_{\text {appl }}$ giving a V-shaped curve. The negative slope found for shorter cracks corresponds to the data to the left of the inflection point " $x$ " in Fig. 13. Such behavior has been reported in the past and is generally termed "short-crack behavior." 8,11 Beyond a certain crack length, or stress intensity factor, corresponding to a minimum crack growth rate or the inflection point " $x$ " in Fig. 13, the normal fatigue crack propagation behavior gradually resumes and the positive dependence on the applied stress intensity factor is again obeyed.

As recognized by Hoshida et al., ${ }^{39}$ the anomalous growth behavior can be qualitatively understood using linear elastic fracture mechanics developed for indentation fracture

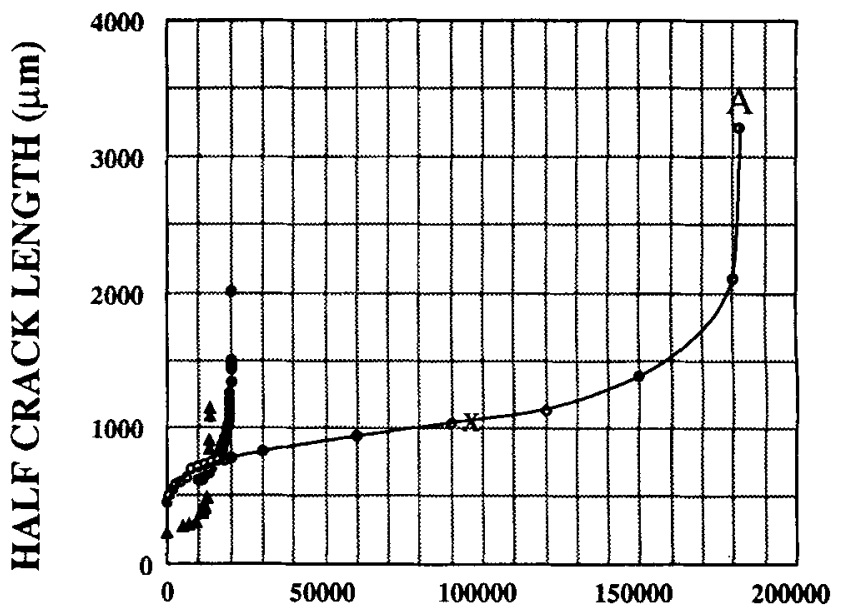

\section{CYCLES}

Fig. 13. Half crack length vs fatigue cycles. Filled symbols from two annealed specimens and open circles from an unannealed specimen. 


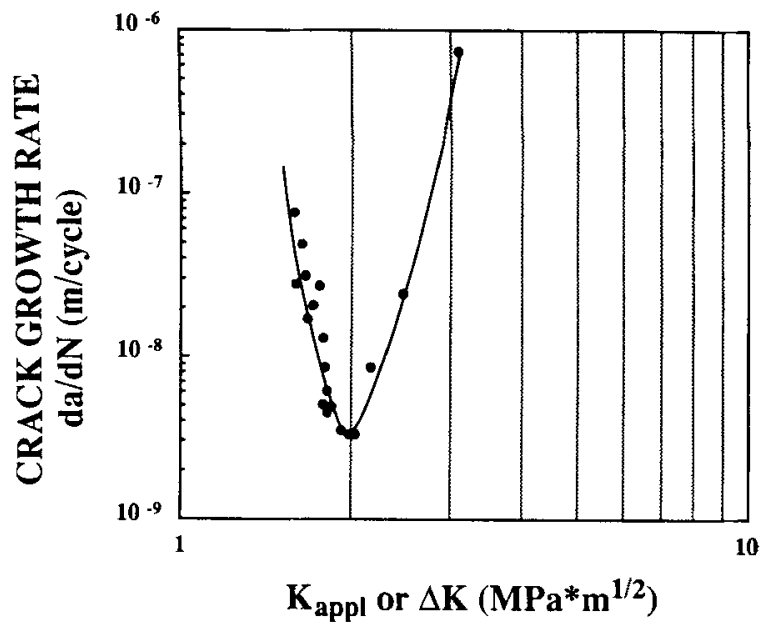

Fig. 14. Fatigue crack growth rate vs applied stress intensity factor (same as stress intensity range).

(Fig. 15). In addition to the applied stress intensity factor ( $\left.K_{\text {appl }}\right)$, a stress intensity factor due to the residual stress $\left(K_{\text {res }}\right)$ should be considered. ${ }^{39}$ The latter is customarily represented as

$$
K_{\text {res }}=\chi P a^{-3 / 2}
$$

where $P$ is the indentation load and $\chi$ is a material and geometrical constant. Equation (8) can be further simplified by noting that

$$
K_{\mathrm{IC}}=\chi P a_{0}{ }^{-3 / 2}
$$

where $K_{\mathrm{IC}}$ is the fracture toughness and $a_{0}$ is the crack length determined from the initial indentation experiment. Thus

$$
K_{\mathrm{res}}=K_{\mathrm{IC}}\left(a_{0} / a\right)^{3 / 2}
$$

The effective stress intensity factor $\left(K_{\text {eff }}\right)$ in an unannealed specimen is $K_{\text {appl }}+K_{\text {res }}$. These contributions are plotted in Fig. 15, which clearly demonstrates that while $K_{\text {appl }}$ increases monotonically with crack extension, $K_{\text {eff }}$ experiences a minimum because of the rapid decay of $K_{\text {res }}$. Thus, the behavior of the anomalous crack growth rate in the presence of a residual stress can be conceptually understood.
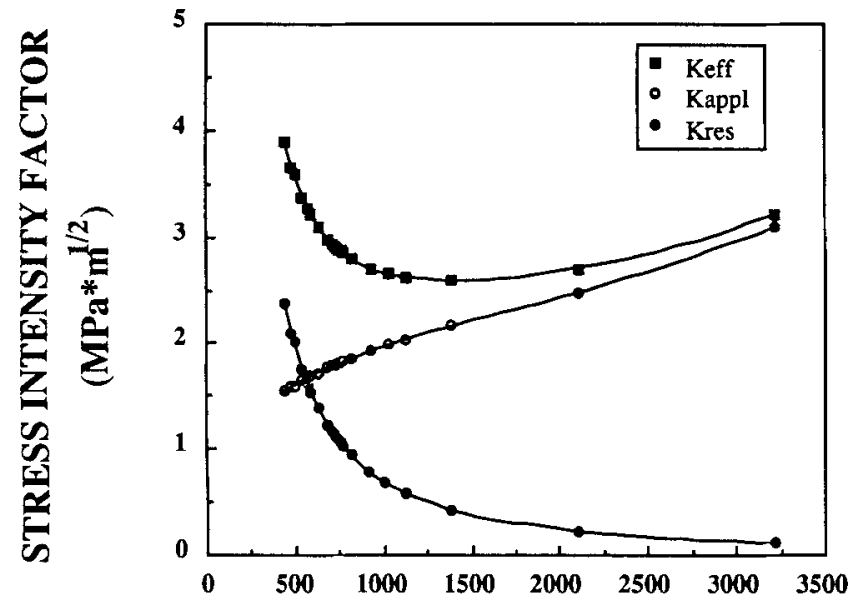

HALF CRACK LENGTH $(\mu \mathrm{m})$

Fig. 15. Effective stress intensity factor $\left(K_{\text {eff }}\right)$, applied stress intensity factor $\left(K_{\text {appl }}\right)$, and residual stress intensity factor $\left(K_{\text {res }}\right)$ vs half crack length. For $K_{\text {eff }}$ and $K_{\text {appl }}$, only the maximum is shown $\left(\Delta K=K_{\text {appl }}\right)$.
A closer examination of Fig. 15 finds that the minimum of $K_{\text {eff }}$ lies at a crack length of $1400 \mu \mathrm{m}$, whereas the minimum growth rate of Fig. 13 occurs at about $1100 \mu \mathrm{m}$. This discrepancy could be due to the inaccuracy of Eq. (10). Alternatively, if we adopt the same growth equation, Eq. (7), and evaluate the combined effect of $K_{\text {eff }}$ and $\Delta K$ (which equals $K_{\text {appl }}$ since $R=0$ ), we find the predicted minimum growth rate now occurs at $1200 \mu \mathrm{m}$, in better agreement with the data. Indeed, the normalized fatigue crack growth rate in the presence of a residual stress, shown in Fig. 16, is essentially indistinguishable from that without a residual stress, shown in Fig. 8. Thus, the growth equation, Eq. (7), is consistent with the data for fatigue crack growth through a residual stress field.

Actually, the experiment on the unannealed specimen has provided a direct confirmation that fatigue crack growth is not controlled by $\Delta K$ only. Otherwise, since $\Delta K=K_{\text {app }}$, and increases monotonically, there should be no grow th rate minimum at all. The incorporation of $K_{\max }$ is thus important for understanding these data. On the other hand, if the fatigue crack growth rate does additionally depend on $\Delta K$, then the growth rate minimum must always occur at a crack size smaller than that for the minimum in the peak $K_{\text {eff }}$ because $\Delta K$ is increasing. This is believed to be the case here.

\section{Discussion}

\section{(1) Fatigue Lifetime Prediction}

In the previous paper, a fatigue crack growth rate equation of the form of Eq. (1) was used to arrive at an expression for the $S-N$ curve..$^{35}$ By comparing its predicted fatigue lifetime with the experimentally measured ones, we have obtained the prefactor $A$ (see Table III of the previous paper) for various $R$ ratios. The inferred crack growth rate from the previous paper, shown as solid lines in Fig. 6 in the present paper, are in reasonably good agreement with the data of direct crack growth measurements using controlled flaws. Given the rather different test procedure and the specimen geometry, one in uniaxial tension-compression and with small internal cracks from preexisting natural flaws and the other in bending and with longer controlled surface flaws from indentation, the agreement between these two sets of data is indeed encouraging. The observation that the crack growth rate in the presence of a residual stress behaves similarly once the additional contribution of the residual stress to the stress intensity factor is accounted for gives further credence to the notion of a unique crack growth rate for a given stress intensity factor and $R$ ratio.

We can now claim that the fatigue lifetime of a smooth specimen is controlled by the propagation of preexisting flaws

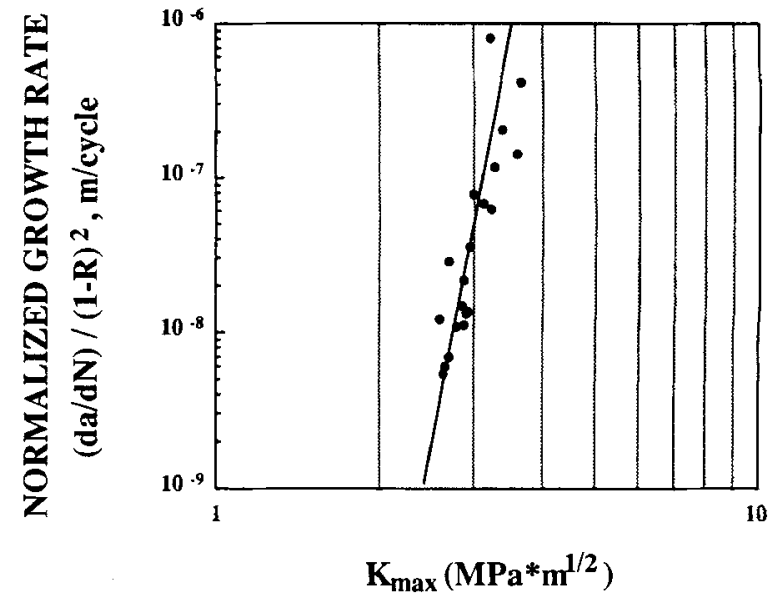

Fig. 16. Normalized crack growth rate vs maximum (effective) stress intensity factor. 
in 3Y-TZP. Surface nucleation of fatigue cracks is not thought to be important, although preexisting flaws in the near surface region can be rather damaging because of a higher stress concentration factor. ${ }^{35}$ It was further argued in the previous paper that much of the observations in 3Y-TZP are probably general for most brittle ceramics. This is believed to hold for lifetime prediction as well.

\section{(2) Mechanisms of Fatigue Crack Propagation}

The crack growth law expressed by Eq. (7) provides important clues to the possible mechanisms of fatigue crack propagation in this material. From a mechanics point of view, a $\Delta K^{2}$ dependence is suggestive of crack tip plastic deformation since both the cyclic plastic zone size and the cyclic crack tip opening displacement (CTOD) have the same dependence. ${ }^{40}$ In the literature on fatigue of metals and polymers, the connection with the cyclic plastic zone size can be extended to include damage accumulation to account for crack extension, while the connection with the cyclic CTOD can be related to irreversible crack tip blunting, which can also result in crack growth. ${ }^{40}$ A slightly stronger dependence, such as the $\Delta K^{4}$ dependence, commonly known as the Paris law for metals, ${ }^{34,41}$ can be rationalized in the same manner by using a different damage criterion in conjunction with the above mechanics argument ${ }^{40}$ In view of the similar $\Delta K$ dependence observed here, we will tentatively ascribe a plasticity-controlled mechanism (most likely that of microcracking, as suggested in the previous paper ${ }^{35}$ ) to 3 Y-TZP. It is further noted that Dauskardt et $a l .^{10}$ have also reported limited data consistent with a $\Delta K^{2}$ dependence for Mg-PSZ, which has a rather large component of plastic strain at tensile fracture. ${ }^{42}$ Thus, it seems likely that the main accelerating mechanism of a cyclic stress on crack growth may be similar in both ceramics and directly related to crack tip plasticity, even though the magnitude of ceramic plasticity is rather different in the two cases.

To incorporate the above ideas into a form consistent with our crack growth data, we propose the following phenomenological equation in place of Eq. (7):

$$
\mathrm{d} a / \mathrm{d} N=B\left(K_{\max } / K_{\mathrm{IC}}\right)^{n}\left[\Delta K^{2} /\left(\sigma^{*} E\right)\right]
$$

Here, $\sigma^{*}$ is a characteristic stress for crack tip plasticity at the crack tip (such as transformation stress ${ }^{43,44}$ or microcracking stress ${ }^{7}$ ), $E$ is Young's modulus, and $K_{\mathrm{IC}}$ is the fracture toughness. In the above, $n=m-2$ to be consistent with Eq. (1), whereas $\Delta K^{2} / \sigma^{*} E$ is essentially the CTOD. Note that $B$ is a dimensionless constant which should be substantially independent of the mechanical test parameters $\left(K_{\max }, R\right.$, and $\left.\Delta K\right)$ and materials parameters $\left(E, \sigma^{*}\right.$, and $\left.K_{\mathrm{IC}}\right)$. On the other hand, it can be readily shown that, in Eq. (1)

$$
A=B /\left[\sigma^{*} E(1-R)^{n} K_{\mathrm{IC}}^{n}\right]
$$

Therefore, $A$ is a constant which is very sensitive to both test parameters and materials parameters, and has a dimension which varies with $n$.

Among the data in the literature, some of Dauskardt et al.' ${ }^{10}$ on Mg-PSZ seem to come from materials of substantially the same microstructure but somewhat different $K_{\mathrm{IC}}$ and probably different transformation stresses. (The exponent $m$ is the same, $m=24$.) These data are summarized in Table II. From them, we can estimate $B / \sigma^{*}$, which is also listed in Table II. These limited results indicate that as $K_{\text {IC }}$ increases, $\sigma^{*}$ decreases, which is reasonable for transformation-toughened materials. ${ }^{43}$ Thus, this qualitative agreement is encouraging. Further studies of fatigue crack growth with controlled variations of materials and testing parameters are much required to test the above proposal more critically.

We have alluded to the transformation plasticity that operates extensively in Mg-PSZ. (Evidence of transformation plasticity operating in fatigue for $\mathrm{Mg}-\mathrm{PSZ}$ was previously provided by hysteresis in uniaxial tension-compression testing. ${ }^{13}$ ) For 3Y-TZP, experiments reported in the previous paper have identified microcracking as the most likely mechanism for plastic strain accumulation. ${ }^{35}$ This microcracking mechanism can be regarded as pseudoplastic, in that it is distinct from the classical plastic deformation due to dislocation slip. In terms of the magnitude of strain, it is also much smaller than the classical plastic deformation in metals and polymers. Nevertheless, from a mechanical point of view, this inelastic mechanism can still be responsible for crack tip deformation and damage. ${ }^{7,40}$ Presumably, other pseudoplastic deformation modes in ceramics, such as transformation plasticity or twinning (domain switching), can also be responsible for fatigue damage and crack propagation.

Although the mechanism of pseudoplastic strain is believed to be responsible for ceramic fatigue, it does not provide a direct explanation for the very steep dependence of the crack growth rate on the maximum stress intensity factor. The present study provides a direct confirmation of this dependence for 3Y-TZP. A reexamination of the $\mathrm{Mg}$-PSZ data has also found that the apparently steep $\Delta K$ dependence is actually due to a steep $K_{\max }$ dependence. Since such a dependence is common for both ceramics with a very pronounced $R$-curve (such as Mg-PSZ) and without (such as Y-TZP), we suspect this steep dependence is probably unrelated to the details and the spatial extent of the crack tip shielding mechanism. Most likely, it is an inherent feature of crack propagation kinetics in very brittle materials.

\section{(3) Striations}

Fatigue striations reported in this study are different in origin from the ones commonly observed in metals and polymers. ${ }^{34}$ They are actually the demarcations between fatigue fracture and overload fracture, which appear as alternating light and dark damage bands, as explained in Section III(4). When crack growth is entirely in the fatigue regime, as in regime II of Fig. 11, no striations should appear.

Although striations are not associated with fatigue crack growth in ceramics, the different appearance of the fatigue fracture step and the overload fracture step strongly suggests that these two processes proceed in two very different ways, so that their fracture topography is sufficiently different from each other to be discernible. Whether the different topography implies a different crack growth mechanism is harder to ascertain, although this seems highly possible in view of the discussion in Section IV(2).

As we have shown in Fig. 11, a $K_{\max }-a$ curve with a very flat slope in regime III provides a favorable mechanical condition for fatigue striations to appear, because catastrophic overload fracture can be more easily suppressed by rapid unloading during stress cycling. The shape of the $K_{\max }-a$ curve, however, is very much dependent on the specimen geometry and crack length. For indentation cracks studied here, these $K_{\max }-a$ curves follow approximately $K_{\max } \propto a^{n}$, with $n \approx 0.3$. Thus, they rise very gently. In the compact tension specimen, on the other hand, the $K_{\max }-a$ curve has a concave upward curvature. ${ }^{45}$ Thus, it is difficult to observe fatigue striations in ceramic specimens using the latter geometry.

Table II. Fatigue Data of Two Mg-PSZ ${ }^{10}$

\begin{tabular}{ccccccc}
\hline Mg-PSZ & $\begin{array}{c}K_{\mathrm{IC}} \\
\left(\mathrm{MPa}^{1 / 2}\right)\end{array}$ & $A^{\dagger}$ & $m$ & $R$ & $\begin{array}{c}E \\
(\mathrm{GPa})\end{array}$ & $\begin{array}{c}B / \sigma^{*} \\
\left(\mathrm{MPa}^{-1}\right)\end{array}$ \\
\hline Low toughness (AF) & 5.5 & $4.89 \times 10^{-22}$ & 24 & 0.1 & 208 & 0.20 \\
Mid toughness (MS) & 11.5 & $5.70 \times 10^{-28}$ & 24 & 0.1 & 208 & 2.53 \\
\hline
\end{tabular}




\section{(4) - Short-Crack Behavior}

The V-shaped $\mathrm{d} a / \mathrm{d} N-K_{\max }$ or $\Delta K$ correlation is representative of the so-called "short-crack behavior." The inverse dependence on the stress intensity factor is unusual and not expected for long cracks. For metals, short-crack behavior is often observed (a) when the crack size is shorter than the characteristic length of microstructural feature, (b) when the crack size is shorter than the characteristic range of residual stress, (c) when the crack size is so small that the required applied stress for fracture exceeds that for yield, and/or (d) when the crack size is so small that crack closure does not occur in unloading. ${ }^{46}$ In the present study, 3Y-TZP has a grain size smaller than $0.5 \mu \mathrm{m}$ and a transformation zone width no more than a few micrometers, whereas the typical failurecausing natural flaws, having a size of $25 \mu \mathrm{m}$, are 1 to 2 orders of magnitude larger than the characteristic length of the microstructure. Meanwhile, the yield stress of ceramics is almost always much higher than the applied stress when fracture ensues. Although the crack closure effect has not been evaluated quantitatively, our experiments on unannealed indentation cracks have demonstrated that residual stress can be directly responsible for an apparent "short-crack behavior." This could very well be the case for similar behavior in other ceramics with fine microstructures and a steep $R$-curve. Since natural life-determining flaws are typically several tens to hundreds of micrometers in size, further studies on their growth, with and without residual stress, are important and should be conducted in order to definitively ascertain a unique growth law for brittle ceramic materials.

\section{Conclusions}

(1) Under a variety of mechanical conditions, the fatigue crack growth rate was measured using controlled surface flaws having the size of several hundred micrometers. A unique growth law strongly dependent on the maximum stress intensity factor and quadratically dependent on the amplitude of the cyclic stress intensity factor has emerged. This growth law is also consistent with the lifetime data under uniaxial tension-compression and the crack extension rate under a residual stress.

(2) The fatigue lifetime of 3Y-TZP is controlled by the growth of preexisting flaws. Knowing the size and geometry of preexisting flaws and the crack growth law, the fatigue lifetime can be estimated, albeit the very strong dependence of crack growth rates on the applied stress could result in an enormous sensitivity of the predicted life to both the initial defect size and the assumption of the in-service loads.

(3) The apparent "short-crack behavior" of indent cracks exhibiting an inverse growth rate dependence on the applied stress intensity factor in 3Y-TZP is found to be an artifact. By including the residual stress contribution, the growth rate is shown to be in accordance with the other growth data of preexisting flaws free from residual stress.

(4) Fatigue striations for 3Y-TZP form when overload fracture and fatigue fracture alternate successively during cyclic loading. The appearance of these features varies with the $R$ ratio and is very sensitive to the loading condition and crack geometry.

(5) Fatigue crack growth in ceramics is suggested to follow a microplasticity-related mechanism, but the very steep dependence on the maximum stress intensity factor is likely to be an inherent feature of brittle crack growth. Microcracking is a plausible general explanation for microplasticity.

\section{References}

'L. Ewart and S. Suresh, "Dynamic Fatigue Crack Growth in Polycrystalline Alumina under Cyclic Compression," J. Mater. Sci. Lett., 5, 744-48 (1986).

${ }^{2}$ L. Ewart and S. Suresh, "Crack Propagation in Ceramics under Cyclic Loads," J. Mater. Sci., 22, 1173-92 (1987)

${ }^{3}$ R. H. Dauskardt, W. Yu, and R. O. Ritchie, "Fatigue Crack Propagation in Transformation-Toughened Zirconia Ceramic," I. Am. Ceram. Soc., 70
[10] C-248-C-52 (1987).

${ }^{4}$ M.V. Swain and V. Zelizko, "Comparison of Static and Cyclic Fatigue on Mg-PSZ Alloys;" pp. 595-606 in Advances in Ceramics, Vol. 24B, Science and Technology of Zirconia III. Edited by S. Sōmiya, N. Yamamoto, and H. Hanagida. American Ceramic Society, Westerville, OH, 1988.

${ }^{5}$ V. Zelizko, A. Grossmuller, and M.V. Swain, "Environment Assisted Fatigue Crack Growth Behavior of Mg-PSZ," Mater. Sci. Forum., 34-36, 201205 (1988)

${ }^{6} \mathrm{~V}$. Zelizko and M.V. Swain, "Influence of Surface Preparation on the Rotating Flexural Fatigue of Mg-PSZ," J. Mater. Sci., 23, 1077-82 (1988).

${ }^{7}$ S. Suresh and J. R. Brockenbrough, "Theory and Experiments of Fracture in Cyclic Compression: Single Phase Ceramics, Transforming Ceramics and Ceramic Composites," Acta Metall., 36 [6] 1455-70 (1988).

${ }^{8}$ D. G. Jensen, V. Zelizko, and M.V. Swain, "Small Flaw Static Fatigue Crack Growth in Mg-PSZ," J. Mater. Sci. Lett., 8, 1154-57 (1989).

${ }^{9}$ L. A. Sylva and S. Suresh, "Crack Growth in Transforming Ceramics under Cyclic Tensile Loads," J. Mater. Sci., 24, 1729-38 (1989).

${ }^{10}$ R. H. Dauskardt, D. B. Marshall, and R. O. Ritchie, "Cyclic FatigueCrack Propagation in Magnesia-Partially-Stabilized Zirconia Ceramics," J. Am. Ceram. Soc., 73 [4] 893-903 (1990).

"A. A. Steffen, R. H. Dauskardt, and R. O. Ritchie, "Cyclic FatigueCrack Propagation in Ceramics: Long and Small Crack Behavior"; pp. 74552 in Fatigue 90, Proceedings of the Fourth International Conference on Fatigue and Fatigue Thresholds. Edited by $\mathrm{H}$. Kitagawa and T. Tanaka. Materials and Component Engineering Publications Ltd., Birmingham, U.K., 1990.

${ }^{12}$ R. H. Dauskardt, W. C. Carter, D. K. Veirs, and R. O. Ritchie, "Transient Subcritical Crack-Growth Behavior in Transformation-Toughened Ceramics," Acta Metall, in press.

${ }^{13}$ K. J. Bowman, P. E. Reyes-Morel, and I-W. Chen, "Reversible Transformation Plasticity in Uniaxial Tension-Compression Cycling of Mg-PSZ," Mater. Res. Soc. Symp. Proc., 78, 51-58 (1987).

${ }^{14}$ B. K. Sarkar and T.G.T. Glinn, "Fatigue Behavior of High- $\mathrm{Al}_{2} \mathrm{O}_{3} \mathrm{Ce}-$ ramics," Trans. Br. Ceram. Soc., 69, 199-203 (1970).

${ }^{15}$ D. A. Krohn and D. P. H. Hasselman, "Static and Cyclic Fatigue Behavior of a Polycrystalline Alumina," J. Am. Ceram. Soc. 55 [4] 208-11 (1972).

${ }^{16}$ C. P. Chen and W. J. Knapp, "Fatigue Fracture of an Alumina Ceramic at Several Temperatures"; pp. 691-707 in Fracture Mechanics of Ceramics, Vol. 2. Edited by R. C. Bradt, A. G. Evans, D. P. H. Hasselman, and F. F Lange. Plenum Press, New York, 1973.

${ }^{17}$ H. N. Ko, "Fatigue Strength of Sintered $\mathrm{Al}_{2} \mathrm{O}_{3}$ under Rotary Bending," J. Mater. Sci. Lett., 5, 464-66 (1986).

${ }^{18} \mathrm{H} . \mathrm{N}$. Ko, "Cyclic Fatigue Behavior of Sintered $\mathrm{Al}_{2} \mathrm{O}_{3}$ under Rotary Bending," J. Mater. Sci. Lett., 6, 801-805 (1987).

${ }^{19}$ I. Maekawa, H. Shibata, and A. Kobayashi, "Bending Fatigue of $\mathrm{Al}_{2} \mathrm{O}_{3}-$ $\mathrm{ZrO}_{2}$ Ceramics," J. Soc. Mater. Sci., Jpn., 36 [409] 1116-27 (1987).

${ }^{20}$ M. J. Reece, F. Guiu, and M. F. R. Sammur, "Cyclic Fatigue Crack Propagation in Alumina under Direct Tension-Compression Loading," J. Am Ceram. Soc., 72 [2] 348-52 (1989).

${ }^{21}$ H. Kamiya, M. Takatsu, K. Ohya, M. Ando, and A. Hattori, "Effect of Microstructure on Cyclic Fatigue Properties of $\mathrm{Al}_{2} \mathrm{O}_{3}$ Ceramics and $\mathrm{Al}_{2} \mathrm{O}_{3}$ Composites," J. Jpn. Ceram. Soc., 98 [5] 456-63 (1990).

${ }^{22}$ D. C. Cardona and C. J. Beevers, "Fatigue Behavior of Zirconia-Ceria Alloys"; pp. 1023-29 in Fatigue 90, Proceedings of the Fourth International Conference on Fatigue and Fatigue Thresholds. Edited by $\mathrm{H}$. Kitagawa and T. Tanaka. Materials and Component Engineering Publications Ltd., Birmingham, U.K., 1990.

${ }^{23}$ J.F. Tsai, C. S. Yu, and D. K. Shetty, "Fatigue Crack Propagation in Ceria-Partially-Stabilized Zirconia (Ce-TZP)-Alumina Composites," J. Am. Ceram. Soc., 73 [10] 2992-3001 (1990).

${ }^{24} \mathrm{R}$. Kossowsky, "Cyclic Fatigue of Hot-Pressed $\mathrm{Si}_{3} \mathrm{~N}_{4}$," J. Am. Ceram. Soc., 56 [10] 531-35 (1973)

${ }^{25}$ Y. Yamauchi, S. Sakai, M. Ito, T. Ohji, W. Kanematsu, and S. Ito, "Fatigue Test for $\mathrm{HP}-\mathrm{Si}_{3} \mathrm{~N}_{4}$ Ceramics Indented with Knoop Pyramid," Yogyo Kyokaishi, 94 [7] 631-35 (1986).

${ }^{26} \mathrm{~T}$. Kawakubo and K. Komeya, "Static and Cyclic Fatigue Behavior of a Sintered Silicon Nitride at Room Temperature," J. Am. Ceram. Soc., 70 [6] 400-405 (1987).

${ }^{27}$ M. Masuda, T. Soma, M. Matsui, and I. Oda, "Fatigue of Ceramics (Part 1)-Fatigue Behavior of Sintered $\mathrm{Si}_{3} \mathrm{~N}_{4}$ under Tension-Compression Cyclic Stress," J. Jpn. Ceram. Soc., 96 [3] 277-83 (1988).

${ }^{28} \mathrm{~S}$. Horibe, "Cyclic Fatigue Crack Growth from Indentation Flaw in $\mathrm{Si}_{3} \mathrm{~N}_{4}, "$ J. Mater. Sci. Lett., 7 [7] 725-27 (1988).

${ }^{29}$ M. Masuda, N. Yamada, T. Soma, M. Matsui, and I. Oda, "Fatigue of Ceramics (Part 2)-Cyclic Fatigue Properties of Sintered $\mathrm{Si}_{3} \mathrm{~N}_{4}$ at Room Temperature," J. Jpn. Ceram. Soc., 97 [5] 520-24 (1989).

${ }^{30}$ M. Masuda, T. Soma, M. Matsui, and I. Oda, "Fatigue of Ceramics (Part 3)-Cyclic Fatigue Behavior of Sintered $\mathrm{Si}_{3} \mathrm{~N}_{4}$ at High Temperature," J. Jpn. Ceram. Soc., 97 [6] 612-18 (1989).

${ }^{31} \mathrm{H}$. Kishimoto, A. Ueno, and H. Kawamoto, "Crack Propagation Behavior of $\mathrm{Si}_{3} \mathrm{~N}_{4}$ under Cyclic Loads-Influence of Difference in Materials"; pp. 727-32 in Fatigue 90, Proceedings of the Fourth International Conference on Fatigue and Fatigue Thresholds. Edited by H. Kitagawa and T. Tanaka. Materials and Component Engineering Publications Ltd., Birmingham, U.K., 1990.

${ }^{32}$ A. Ueno, H. Kishimoto, H. Kawamoto, and M. Asakura, "Crack Propagation Behavior of Sintered Silicon Nitride under Cyclic Load of High Stress Ratio and High Frequency"; pp. 733-38 in Fatigue 90, Proceedings of the Fourth International Conference on Fatigue and Fatigue Thresholds. Edited by H. Kitagawa and T. Tanaka. Materials and Component Engineering Pub- 
lications Ltd., Birmingham, U.K., 1990.

${ }^{33}$ M. Takatsu, K. Ohya, and M. Ando, "The Relationship between Cyclic Fatigue Properties and Microstructures of Sintered Silicon Nitride Ceramics," J. Jpn. Ceram. Soc., 98 [5] 490-98 (1990).

${ }^{34}$ See, for example, R.W. Hertzberg, Deformation and Fracture Mechanics of Engineering Materials, 3d ed.; pp. 475-604. Wiley, New York, 1989.

${ }^{35}$ S.-Y. Liu and I-W. Chen, "Fatigue of Yttria-Stabilized Zirconia: I, Fatigue Damage, Fracture Origins, and Lifetime Prediction," J. Am. Ceram. Soc., 74 [6] 1197-205 (1991).

${ }^{36}$ R. M. Anderson and L. M. Braun, "Technique for the $R$-Curve Determination of Y-TZP Using Indentation-Produced Flaws," J. Am. Ceram. Soc., 73 [10] 3059-62 (1990).

${ }^{37}$ ASTM Standard E.740-80, "Standard Recommended Practice for Fracture Testing with Surface-Crack Tension Specimens," ASTM Annual Book of Standards, Vol. 3.01; pp. 740-50. American Society for Testing and Materials, Philadelphia, PA, 1983.

38 J. C. Newman, Jr, and I. S. Raju, "Analyses of Surface Crack in Finite Plates Under Tension or Bending Loads," NASA Technical Paper 1578 (available from National Technical Information Service, Springfield,
VA), 1979.

${ }^{39}$ T. Hoshide, T. Ohara, and T. Yamada, "Fatigue Crack Growth from Indentation Flaw in Ceramics," Int. J. Fract., 37, 47-59 (1988).

${ }^{40} J$. R. Rice, "Mechanics of Crack Tip Deformation and Extension by Fatigue," ASTM Spec. Tech. Publ., 415, 247-311 (1967).

${ }^{41}$ P. C. Paris, "The Growth of Cracks Due to Variations in Loads"; Ph.D. Thesis. Lehigh University, Bethlehem, PA, 1962.

${ }^{42}$ D. B. Marshall, "Strength Characteristics of Transformation-Toughened Zirconia," J. Am. Ceram. Soc., 69 [3] 173-80 (1986).

${ }^{43} \mathrm{I}-\mathrm{W}$. Chen and P. E. Reyes-Morel, "Implications of Transformation Plasticity in $\mathrm{ZrO}_{2}$-Containing Ceramics: I, Shear and Dilatation Effects," J. Am. Ceram. Soc., 69 [3] 181-89 (1986).

${ }^{44} \mathrm{P}$. E. Reyes-Morel and I-W. Chen, "Transformation Plasticity of $\mathrm{CeO}_{2}$ Stabilized Tetragonal Zirconia Polycrystals: I, Stress Assistance and Autocatalysis," J. Am. Ceram. Soc., 71 [5] 343-53 (1988).

${ }^{45}$ H. Tada, P. Paris, and G. Irwin, The Stress Analysis of Cracks Handbook. Delph Corp., Hellertown, PA, 1973.

${ }^{46}$ R. O. Ritchie and J. Lankford, Small Fatigue Cracks. Metallurgical Society, Warrendale, PA, 1986. 